\title{
Unexpected decline in tuberculosis cases coincident with economic recession - United States, 2009
}

\author{
Carla A Winston ${ }^{1 *}$, Thomas R Navin ${ }^{1}$, Jose E Becerra, Michael P Chen ${ }^{1}$, Lori R Armstrong ${ }^{1}$, Carla Jeffries ${ }^{2}$, \\ Rachel S Yelk Woodruff', Jessie Wing ${ }^{1}$, Angela M Starks' ${ }^{1}$ Craig M Hales ${ }^{3}$, J Steve Kammerer ${ }^{2}$, \\ William R Mac Kenzie1, Kiren Mitruka1, Mark C Miner', Sandy Price², Joseph Scavotto', Ann M Cronin', \\ Phillip Griffin ${ }^{4}$, Philip A LoBue ${ }^{1}$ and Kenneth G Castro ${ }^{1}$
}

\begin{abstract}
Background: Since 1953, through the cooperation of state and local health departments, the U.S. Centers for Disease Control and Prevention (CDC) has collected information on incident cases of tuberculosis (TB) disease in the United States. In 2009, TB case rates declined -11.4\%, compared to an average annual -3.8\% decline since 2000. The unexpectedly large decline raised concerns that TB cases may have gone unreported. To address the unexpected decline, we examined trends from multiple sources on TB treatment initiation, medication sales, and laboratory and genotyping data on culture-positive TB.

Methods: We analyzed 142,174 incident TB cases reported to the U. S. National Tuberculosis Surveillance System (NTSS) during January 1, 2000-December 31, 2009; TB control program data from 59 public health reporting areas; self-reported data from 50 CDC-funded public health laboratories; monthly electronic prescription claims for new TB therapy prescriptions; and complete genotyping results available for NTSS cases. Accounting for prior trends using regression and time-series analyses, we calculated the deviation between observed and expected TB cases in 2009 according to patient and clinical characteristics, and assessed at what point in time the deviation occurred.

Results: The overall deviation in TB cases in 2009 was $-7.9 \%$, with -994 fewer cases reported than expected $(P<$ .001). We ruled out evidence of surveillance underreporting since declines were seen in states that used new software for case reporting in 2009 as well as states that did not, and we found no cases unreported to CDC in our examination of over 5400 individual line-listed reports in 11 areas. TB cases decreased substantially among both foreign-born and U.S.-born persons. The unexpected decline began in late 2008 or early 2009, and may have begun to reverse in late 2009. The decline was greater in terms of case counts among foreign-born than U.S.-born persons; among the foreign-born, the declines were greatest in terms of percentage deviation from expected among persons who had been in the United States less than 2 years. Among U.S.-born persons, the declines in percentage deviation from expected were greatest among homeless persons and substance users. Independent information systems (NTSS, TB prescription claims, and public health laboratories) reported similar patterns of declines. Genotyping data did not suggest sudden decreases in recent transmission.
\end{abstract}

\footnotetext{
* Correspondence: cwinston@cdc.gov

'Division of Tuberculosis Elimination, National Center for HIV/AIDS, Viral Hepatitis, STD, and TB Prevention, Centers for Disease Control and Prevention, 1600 Clifton Road NE, Atlanta, GA, 30333 USA

Full list of author information is available at the end of the article
}

\section{Biomed Central}

(C) 2011 Winston et al; licensee BioMed Central Ltd. This is an Open Access article distributed under the terms of the Creative Commons Attribution License (http://creativecommons.org/licenses/by/2.0), which permits unrestricted use, distribution, and reproduction in any medium, provided the original work is properly cited. 
Conclusions: Our assessments show that the decline in reported TB was not an artifact of changes in surveillance methods; rather, similar declines were found through multiple data sources. While the steady decline of TB cases before 2009 suggests ongoing improvement in TB control, we were not able to identify any substantial change in TB control activities or TB transmission that would account for the abrupt decline in 2009. It is possible that other multiple causes coincident with economic recession in the United States, including decreased immigration and delayed access to medical care, could be related to TB declines. Our findings underscore important needs in addressing health disparities as we move towards TB elimination in the United States.

\section{Background}

Based on National Tuberculosis Surveillance System (NTSS) provisional data in March 2010, the Centers for Disease Control and Prevention (CDC) observed that the decline in reported TB case count in the United States in 2009 was considerably steeper than in recent years [1]. TB case rates declined $-11.4 \%$ in 2009 compared to an average annual $-3.8 \%$ decline since 2000 . Working with internal and external partners, CDC conducted epidemiologic assessments to explore the substantial and unexpected TB decline. We sought to determine if the decline in TB was real, or whether the decline reflected changes in surveillance reporting or diagnosis. We examined evidence that the decline might be due to population changes, improved TB control, or less transmission of TB.

We investigated the extent to which the decline in reported TB might be the result of recent revisions to the NTSS. Health departments in the 50 states and Washington, D.C. electronically report verified cases of TB to the NTSS according to a standard case definition. In 2009, the national TB case definition [2] was modified. Compared with the 1996 version [3], the updated case definition incorporates newer diagnostic tests. Updates to the case definition were coordinated with revisions in the Report of Verified Case of Tuberculosis, the standardized national data collection instrument used to report data to CDC [4]. Major changes to software systems used to report cases electronically to CDC occurred in 2009; specifically, reporting changed from use of a single CDC software, the Tuberculosis Information Management System, to a choice of any software application (including CDC-developed, vendor-developed, and state-developed systems) that is compliant with U.S. National Electronic Disease Surveillance System standards. An additional concern was whether the United States recession from December 2007 through June 2009 [5] might have led to underreporting of TB to $\mathrm{CDC}$, for instance, if routine surveillance could not be conducted due to health department staff reductions. Declines might reflect fewer patients seeking medical care, or physicians considering the diagnosis of TB less often. We also considered the effect of demographic changes in immigration, and of revised overseas TB screening requirements for U.S. immigration applicants that began to be implemented globally in 2007 and may have increased TB diagnoses and treatment prior to immigration, leading to fewer TB diagnoses among immigrants after U.S. entry [6]. Finally, we considered whether the decline might reflect a decrease in TB transmission by examining TB genotype clustering, because localized clustering is assumed to represent recent transmission $[7,8]$.

\section{Methods}

\section{Study population}

TB cases were analyzed for the time period January 1 , 2000, through December 31, 2009, as reported by the 50 states and Washington, D.C., to the NTSS, with data updated through August 27, 2010. NTSS data consist of annual incident cases of TB disease verified according to laboratory or clinical criteria $[2,3]$, and include the month of TB diagnosis verification by public health departments and of TB treatment initiation, patient demographics (age, self-reported race, ethnicity [Hispanic or non-Hispanic], country of origin, social risk factors for TB), and clinical information [9]. Date of symptom onset is not available in the NTSS. Patient insurance status and socioeconomic status are also not available. We analyzed data for foreign-born persons by length of time in the United States and by country of birth. U.S.- or foreign-born designation followed U.S. Census definitions [10].

We collaborated with U.S. TB control officials to validate all individual-level TB case reports for 2008 and 2009 at the county, state, and national level for 10 counties and one large city that together account for onequarter of all TB cases in the United States $23 \%$ in 2008). These areas also provided sentinel information by reporting culture-positive cases of Mycobacterium tuberculosis in the first quarter of 2010 for comparison with 2008 and 2009. We assessed the findings from a survey in March 2010 sponsored by the National Tuberculosis Controllers Association, which solicited potential evidence of changes in surveillance or clinical practice from TB jurisdictions, and we analyzed self-reported data as of August 20, 2010 from 50 CDC-funded public health laboratories (45 states, 3 large cities, Washington 
D.C., and Puerto Rico) to determine the number of suspected TB patients from whom a specimen was submitted for testing and the percentage that were culturepositive for M. tuberculosis complex in 2008 and 2009. To assess trends in TB therapy initiation, we analyzed monthly claims for new combined prescriptions of isoniazid, rifamycins, and pyrazinamide, from January 2004 through March 2010 from CDC BioSense [11], which receives RelayHealth ${ }^{\mathrm{TM}}$ electronic prescription claims for 20,000-30,000 outpatient pharmacies in 50 states and Washington, D.C.. For clustering, we studied all cases reported to the NTSS with complete genotyping results by spoligotyping and 12-locus mycobacterial interspersed repetitive units analysis [12] with TB treatment start dates January 2007 through December 2009. Cases were considered clustered if their $M$. tuberculosis genotype exactly matched another case in the same county in the same year. We calculated clustering percentages by dividing the number of clustered cases by the total cases with genotyping results.

\section{Analyses}

Using NTSS data, we tabulated TB observed case counts for 2009 according to patient characteristics. We logtransformed counts for years 2000 through 2008, and performed linear regression to calculate expected cases and $95 \%$ prediction intervals (PI) for 2009. We calculated the difference between expected and observed 2009 cases, and described the percentage deviation as the difference divided by expected cases, multiplied by 100. We used a Taylor-series approximation to calculate variance for determining $P$ values, which were evaluated for hypothesis generation in conjunction with the magnitude of the deviation and prediction interval bounds. We obtained population denominators from the U.S. Census Bureau Current Population Survey annual March supplement [10] and calculated expected TB case rates and 95\% PI using Poisson regression.

To investigate detailed changes over time, monthly NTSS data for TB treatment start date were used. Because of the seasonal pattern of the data, we constructed autoregressive integrated moving average (ARIMA) models for time series. We used 2000-2007 data to estimate ARIMA parameters and forecast expected monthly counts for 2008 and 2009. ARIMA models were constructed $(\mathrm{p}, \mathrm{d}, \mathrm{q}),(\mathrm{p}, \mathrm{d}, \mathrm{q})_{12}$ to account for first-order (monthly) and second-order (yearly) components for auto-regressive (p), integrated (d), and moving average (q) parameters respectively; the observed data and best-fitting model specified as $(0,1,1)(0,1,1)_{12}$ are shown in Figure 1. We examined differences between observed and expected cases by $P$ values, where

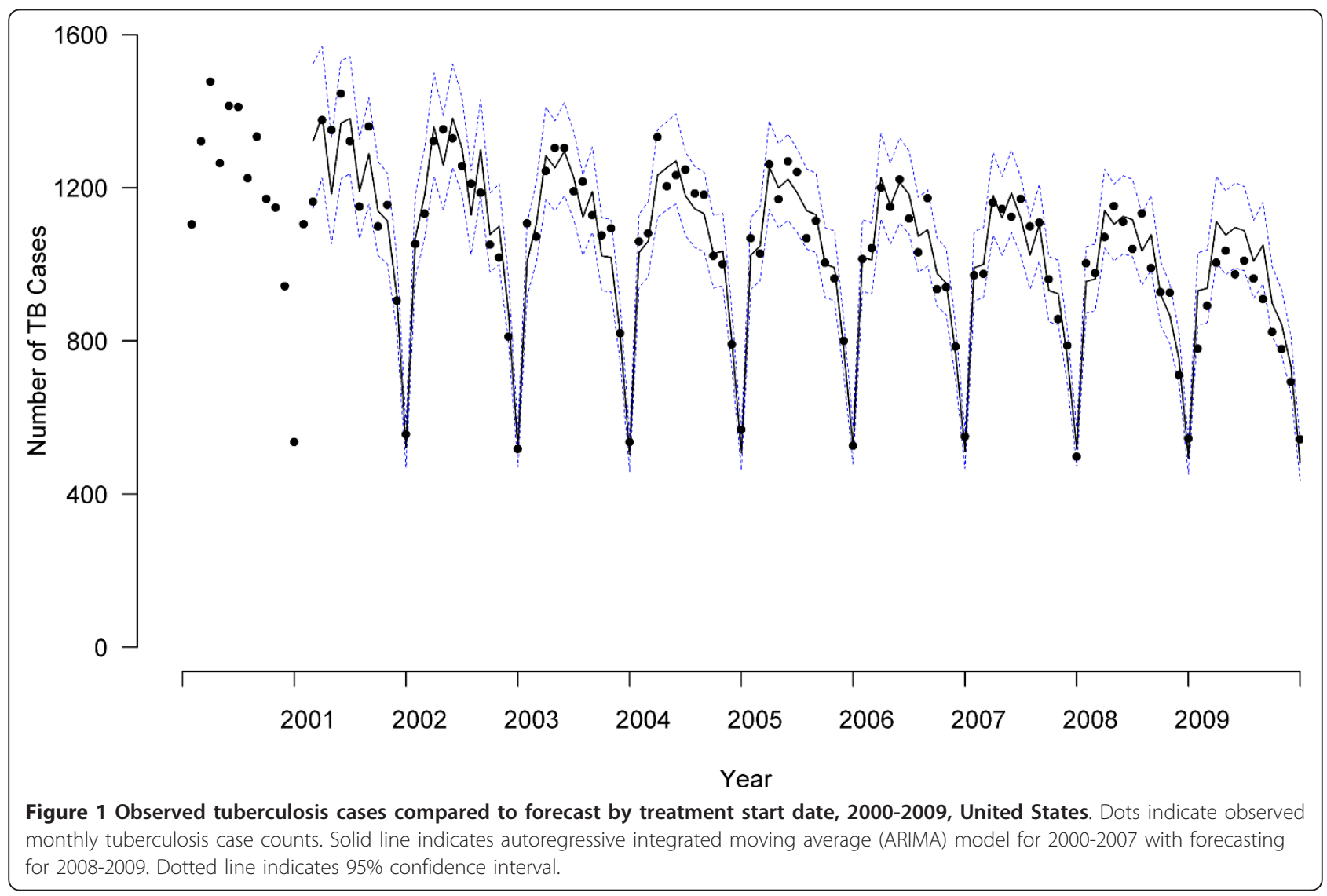


$P<.05$ was interpreted as a significant difference. Similarly, we analyzed monthly BioSense TB medication pharmacy claims using ARIMA models. Since the ARIMA model forecasted a moving average, the first data point reflected the second year of available data for all analyses (2001 for NTSS, 2005 for BioSense). We used the Akaike information criterion and Schwarz criterion as well as examination of autocorrelation and residual plots to evaluate goodness of fit and select best models. Final model fit was assessed using $R^{2}$ as the coefficient of determination.

We used chi-square statistics for categorical comparisons such as the percentage of patients reported positive for $M$. tuberculosis complex by public health laboratories in 2008 versus 2009 and the percentages of genotype clustering by year. Categorical comparisons, regression models, and ARIMA analyses were conducted in SAS (version 9.2; SAS Institute, Cary, NC). We used monthly ARIMA values to fit Joinpoint linear regression models, from which we identified changes in time trends that were significant at $P<.05$. Joinpoint is a statistical software for analysis of trends that starts by assuming no changes in trend, and uses a Monte Carlo permutation method to determine the number of significant flexion points, or changes in trend (Joinpoint version 3.3; Joinpoint, Bethesda, MD) [13].

\section{Results}

\section{Decline in TB cases in 2009}

In 2009, a total of $11,545 \mathrm{~TB}$ cases were reported in the United States. The percentage difference between observed and expected 2009 cases was $-7.9 \%$, with -994 fewer cases reported in 2009 than expected (Table 1). The deviation from expected case counts was significant among both U.S.-born (-7.1\%) and foreign-born (-11.1\%) individuals, and was greatest among foreign-born persons who had been in the United States $<2$ years before TB diagnosis (-23.5\%). Case counts declined $-11.6 \%$ among foreign-born persons from countries that had updated TB screening procedures for immigration by adding sputum culture for high-risk persons and tuberculin skin testing for children [6], compared with $-10.7 \%$ among persons from countries not yet implementing the changes. Of the top 10 countries of origin of foreignborn TB patients, two countries had significant declines: Mexico (-14.8\%), which updated TB screening procedures for immigration in 2007, and Guatemala (-27.0\%), which has not yet begun to implement updated procedures. Demographic strata with significant declines included Hispanics, non-Hispanic blacks, and adults under age 65 (Table 1). TB declines among homeless persons and injecting drug users were $-17.8 \%$ and $-29.6 \%$ greater than expected; these declines were predominantly among U.S.-born TB patients.

\section{TB diagnostic and laboratory findings}

We examined TB diagnostic characteristics to discover potential impacts of the revised 2009 TB case definition. Among cases in the NTSS, the majority (77\%) in 2009 were verified by positive culture of $M$. tuberculosis (Table 1). Among persons aged 15 years and older with culture-positive pulmonary $\mathrm{TB}$, there was a $-14.2 \%$ decline from expected smear-positive cases and an $-18.1 \%$ decline in cavitary disease, with similar declines among the U.S.-born and foreign-born. Unexpected declines were significant among both HIV-infected and uninfected persons (Table 1).

CDC-funded laboratories reported receiving clinical specimens from 103,708 individual patients in 2008 and 97,568 individual patients in 2009 , a $-5.9 \%$ decrease. In 2008, 4,972 (4.8\%) patients had cultures positive for $M$. tuberculosis complex; this dropped to 4,217 (4.3\%) in 2009 , a decline of $-9.8 \%$ in the proportion positive $(P<$ $.001)$.

\section{Surveillance reporting system and state-level analyses}

Declines from expected counts were similar when comparing the 11 states that used the legacy electronic reporting system in $2009(-6.7 \%)$ to the 39 states and Washington D.C. that used newly introduced software systems $(-8.8 \%)$ [Table 1]. Compared to expected case counts, 31 states and Washington, D.C. had case declines; six of the 31 state counts were significantly lower than expected (Florida, Pennsylvania, North Carolina, Minnesota, Maryland, Michigan).

Of TB control program managers from 59 reporting areas, 55 responded to the National Tuberculosis Controllers Association survey (93\%). We received no indication of changes in TB diagnostic or laboratory procedures. We examined the association of case count declines and staff reductions among 29 states reporting more than 100 cases in 2008. Unexpected declines were greatest in the states with no staff reductions $(-21.2 \%)$, followed by states that lost $1-3(-13.9 \%)$, more than 3 and fewer than $10(-8.2 \%)$, or more than $10(-6.1 \%)$ staff positions.

In the 10 counties and one city that matched TB case records across county, state, and national case reports, we did not find any cases unreported to CDC in 2008 $(\mathrm{n}=2,940)$ or $2009(\mathrm{n}=2,496)$. These jurisdictions reported the total number of culture-positive cases as 443 for the first quarter of 2008, decreasing to 344 cases for the first quarter of 2009, but for 2010, increasing to 379 cases in the first quarter.

\section{Time trends in TB treatment initiation and pharmacy sales}

ARIMA analyses showed no difference between 2008 and 2001-2007 TB trends $(P=.90)$, but did show 
Table 1 Observed and expected tuberculosis case counts by select demographic and risk factor characteristics for January-December 2009, United States

\begin{tabular}{|c|c|c|c|c|c|}
\hline & $\begin{array}{l}\text { Observed Case } \\
\text { Count }\end{array}$ & $\begin{array}{l}\text { Expected Case Count } \\
\text { (95\% Prediction } \\
\text { Interval) }\end{array}$ & $\begin{array}{l}\text { Case Count } \\
\text { Difference* }\end{array}$ & $\begin{array}{l}\text { Percentage } \\
\quad \text { of } \\
\text { Expected }\end{array}$ & $\begin{array}{c}P \\
\text { value }\end{array}$ \\
\hline Total & 11545 & $12539(12233-12853)$ & -994 & -7.9 & $<.001$ \\
\hline \multicolumn{6}{|l|}{ Country of origin } \\
\hline Foreign-born & 6854 & $7709(7318-8120)$ & -855 & -11.1 & $<.001$ \\
\hline U.S.-born & 4571 & $4918(4661-5190)$ & -347 & -7.1 & .005 \\
\hline Unknown & 120 & $21(10-48)$ & 99 & 471.4 & .020 \\
\hline \multicolumn{6}{|c|}{ For foreign-born, length of stay in United States } \\
\hline$<2$ years & 1432 & $1872(1590-2204)$ & -440 & -23.5 & $<.001$ \\
\hline$>=2$ years & 4712 & $5197(4865-5551)$ & -485 & -9.3 & .001 \\
\hline Unknown & 710 & $684(599-781)$ & 26 & 3.8 & .587 \\
\hline \multicolumn{6}{|c|}{$\begin{array}{l}\text { For foreign-born, country of origin } \\
\text { according to implementation of } 2007 \\
\text { immigration technical instructions (TI) }\end{array}$} \\
\hline TI countries & 2993 & 3384 (3095 - 3699) & -391 & -11.6 & .002 \\
\hline Non-TI countries & 3861 & $4325(4044-4625)$ & -464 & -10.7 & $<.001$ \\
\hline \multicolumn{6}{|l|}{ Race/ethnicity } \\
\hline Hispanic & 3380 & $3953(3563-4385)$ & -573 & -14.5 & $<.001$ \\
\hline $\begin{array}{c}\text { Non-Hispanic } \\
\text { American Indian }\end{array}$ & 102 & $121(100-148)$ & -19 & -15.7 & .151 \\
\hline $\begin{array}{l}\text { Non-Hispanic } \\
\text { Asian }\end{array}$ & 3192 & $3355(3093-3639)$ & -163 & -4.9 & .186 \\
\hline $\begin{array}{l}\text { Non-Hispanic } \\
\text { Black }\end{array}$ & 2868 & $3135(2963-3317)$ & -267 & -8.5 & .002 \\
\hline $\begin{array}{l}\text { Non-Hispanic } \\
\text { Native Hawaiian }\end{array}$ & 75 & $75(43-130)$ & 0 & 0.0 & 1.00 \\
\hline $\begin{array}{l}\text { Non-Hispanic } \\
\text { White }\end{array}$ & 1829 & $1954(1812-2108)$ & -125 & -6.4 & .085 \\
\hline $\begin{array}{c}\text { Non-Hispanic } \\
\text { Multiple/Unknown }\end{array}$ & 99 & $55(32-95)$ & 44 & 80.0 & .080 \\
\hline \multicolumn{6}{|c|}{ Age at TB diagnosis in years } \\
\hline $0-4$ & 401 & $464(405-532)$ & -63 & -13.6 & .040 \\
\hline $5-14$ & 245 & $292(241-352)$ & -47 & -16.1 & .061 \\
\hline $15-24$ & 1274 & $1494(1360-1641)$ & -220 & -14.7 & $<.001$ \\
\hline $25-44$ & 3893 & $4098(3897-4309)$ & -205 & -5.0 & .048 \\
\hline $45-64$ & 3434 & $3846(3624-4082)$ & -412 & -10.7 & $<.001$ \\
\hline $65+$ & 2292 & $2358(2240-2482)$ & -66 & -2.8 & .339 \\
\hline Unknown & 6 & $1(1-1)$ & 5 & 500.0 & .041 \\
\hline \multicolumn{6}{|l|}{ Disease location } \\
\hline Pulmonary only & 7976 & $8751(8436-9078)$ & -775 & -8.9 & $<.001$ \\
\hline Extrapulmonary only & 2383 & $2594(2465-2730)$ & -211 & -8.1 & .003 \\
\hline Both & 1028 & $1169(1031-1326)$ & -141 & -12.1 & .026 \\
\hline Unknown & 158 & $27(3-211)$ & 131 & 485.2 & .344 \\
\hline \multicolumn{6}{|l|}{ Case verification } \\
\hline Positive culture & 8876 & 9706 (9423 - 9997) & -830 & -8.6 & $<.001$ \\
\hline Positive NAAt & 57 & - & - & - & \\
\hline Positive smear & 91 & $63(45-89)$ & 28 & 44.4 & .084 \\
\hline Clinical case & 1630 & $1426(1243-1637)$ & 204 & 14.3 & .048 \\
\hline Provider diagnosis & 891 & $1364(1246-1492)$ & -473 & -34.7 & $<.001$ \\
\hline
\end{tabular}


Table 1 Observed and expected tuberculosis case counts by select demographic and risk factor characteristics for January-December 2009, United States (Continued)

\begin{tabular}{|c|c|c|c|c|c|}
\hline $\begin{array}{l}\text { Homeless in the year } \\
\text { prior to TB diagnosis }\end{array}$ & & & & & \\
\hline Yes & 571 & $695(623-774)$ & -124 & -17.8 & $<.001$ \\
\hline No & 10797 & $11833(11540-12133)$ & -1036 & -8.8 & $<.001$ \\
\hline Unknown & 177 & $57(22-147)$ & 120 & 210.5 & .094 \\
\hline \multicolumn{6}{|c|}{$\begin{array}{c}\text { Resident of a correctional facility at time of TB } \\
\text { diagnosis }\end{array}$} \\
\hline Yes & 461 & $480(389-593)$ & -19 & -4.0 & .682 \\
\hline No & 11041 & $12055(11796-12319)$ & -1014 & -8.4 & $<.001$ \\
\hline Unknown & 43 & $7(2-29)$ & 36 & 514.3 & .189 \\
\hline \multicolumn{6}{|c|}{$\begin{array}{c}\text { Excess alcohol use in the year prior to TB } \\
\text { diagnosis }\end{array}$} \\
\hline Yes & 1382 & $1528(1414-1652)$ & -146 & -9.6 & .013 \\
\hline No & 9877 & 10889 (10641 - 11144) & -1012 & -9.3 & $<.001$ \\
\hline Unknown & 286 & $180(129-251)$ & 106 & 58.9 & .016 \\
\hline \multicolumn{6}{|c|}{$\begin{array}{l}\text { Injecting drug use in the year prior to TB } \\
\text { diagnosis }\end{array}$} \\
\hline Yes & 152 & $216(182-256)$ & -64 & -29.6 & $<.001$ \\
\hline No & 11087 & $12165(11831-12510)$ & -1078 & -8.9 & $<.001$ \\
\hline Unknown & 306 & $203(129-320)$ & 103 & 50.7 & .093 \\
\hline \multicolumn{6}{|c|}{$\begin{array}{l}\text { Non-injecting drug use in the year prior to TB } \\
\text { diagnosis }\end{array}$} \\
\hline Yes & 828 & $922(829-1026)$ & -94 & -10.2 & .046 \\
\hline No & 10391 & $11438(11178-11703)$ & -1047 & -9.2 & $<.001$ \\
\hline Unknown & 326 & $221(137-355)$ & 105 & 47.5 & .122 \\
\hline \multicolumn{6}{|c|}{ HIV status at time of TB diagnosis } \\
\hline Positive & 706 & $797(748-849)$ & -91 & -11.4 & .005 \\
\hline Negative & 6337 & $7621(7171$ - 8100) & -1284 & -16.8 & $<.001$ \\
\hline Unknown & 4502 & $4347(4134-4572)$ & 155 & 3.6 & .185 \\
\hline \multicolumn{6}{|l|}{ Software for TB reporting $\ddagger$} \\
\hline TIMS & 4455 & $4775(4552-5009)$ & -320 & -6.7 & .004 \\
\hline Other & 7090 & $7771(7470-8084)$ & -681 & -8.8 & $<.001$ \\
\hline
\end{tabular}

*Expected case counts are derived from ratios (i.e., regression slopes on log-transformed observed counts). Because the sum of ratios is not the ratio of the sums, expected case counts stratified on case characteristics do not sum to overall case counts. All stratified count differences sum to within the $95 \%$ prediction interval (-688 to -1308$)$ for the overall case count difference $(-994)$.

+ NAA = nucleic acid amplification test, which was not recorded as a TB case verification criteria until 2009, thus there are no comparable data from which to calculate expected values. In 2009, clinical cases include TB verified by positive interferon gamma release assay (IGRA) in lieu of tuberculin skin test, or by abnormal chest computerized tomography (CT) scan in lieu of chest radiograph; previously, such cases were verified by provider diagnosis because the National Tuberculosis Surveillance System did not collect IGRA or CT scan results prior to 2009.

‡TIMS = Tuberculosis Information Management System in operation since 1998. Other = National Electronic Disease Surveillance System-compliant software newly introduced in 2009.

significant declines for 2009 compared to $2008(P=.01)$, and for 2009 compared to 2001-2007 $(P=.005)$ [Figure 2]. Joinpoint analyses identified two significant changes: a decrease in TB cases starting in October 2008 (95\% confidence interval [CI], February 2007 to March 2009) and an increase in August 2009 (95\% CI, December 2008 to September 2009) [Figure 3]. Joinpoint analyses of BioSense TB prescription claims identified a decrease in March 2008 (95\% CI, October 2007 to June 2008) and an increase in June 2009 (95\% CI, September 2008 to September 2009) [Figure 3].

TB time trends and rates among foreign-born and U.S.born persons

Stratified ARIMA models indicated that case counts in 2009 were lower than expected among both U.S.-born $(P=.04$; Figure 4$)$ and foreign-born $(P=.008$; Figure 5$)$ persons. Joinpoint analyses failed to detect a significant 
change in monthly trend attributed to a single flexion point in time among U.S.-born persons, but did find a significant decrease among foreign-born persons beginning in November 2008 (95\% CI, June 2007 to May 2009) [Figure 3]. When data for foreign-born persons were examined by time since U.S. arrival, a significant decrease was identified in October 2007 (95\% CI, February 2007 to March 2008) among those with less than 2 years between arrival and TB treatment; however, no significant change point in time was identified for foreign-born persons with more than 2 years since arrival. Values of $\mathrm{R}^{2}$ for the ARIMA models ranged from 0.93 to 0.96 , indicating excellent model fit. No outliers were detected for foreign-born or overall TB cases, with three moderately outlying points detected for U.S.-born cases. After adjustment for outliers, the revised $\mathrm{R}^{2}$ for U.S.born changed from 0.93 to 0.94 .

According to Census data, the population of U.S.-born persons in the United States increased 1.1\% in 2009 compared with 2008; in contrast, the population of foreign-born persons fell 1.6\% during this time. The rate of TB in 2009 among U.S.-born persons was 1.7 per 100,000 , compared with an expected 1.9 per 100,000 persons (95\% PI, 1.8 to 1.9). Among foreign-born persons, the rate of TB in 2009 was 18.7 per 100,000 persons, compared with an expected rate of 19.3 per 100,000 (95\% PI, 18.8 to 19.9 ).

\section{TB transmission analyses}

Among foreign-born persons, genotype clustering decreased during $2007-2008$ (26.3\% to $23.2 \%$; $P<.001$ ) and $2008-2009$ (23.2\% to $20.2 \% ; P<.001$ ), while among the U.S.-born, clustering decreased from 2007-2008 (35.5\% to $32.4 \% ; P=.01$ ) but not from 2008-2009 (32.4\% to $31.2 \% ; P=.36)$. Based on published ranges $[14,15]$, we estimated the probability of transmission from a foreign-born source case to a U.S.-born secondary case as between $0.8 \%$ and $4.5 \%$. The decline of -855 foreign-born cases (Table 1) might have resulted in between -38 to -6 fewer U.S.-born secondary cases.

\section{Discussion}

We conclude that observed declines in 2009 TB case counts accurately reflect a true decline in the number of TB cases diagnosed in the United States, and that the deviation from past trends is significant. The unexpected decline in reported TB cases began rather abruptly in late 2008 or early 2009, and may have begun to reverse in mid 2009. We were able to exclude changes in electronic reporting systems as a causal factor, since

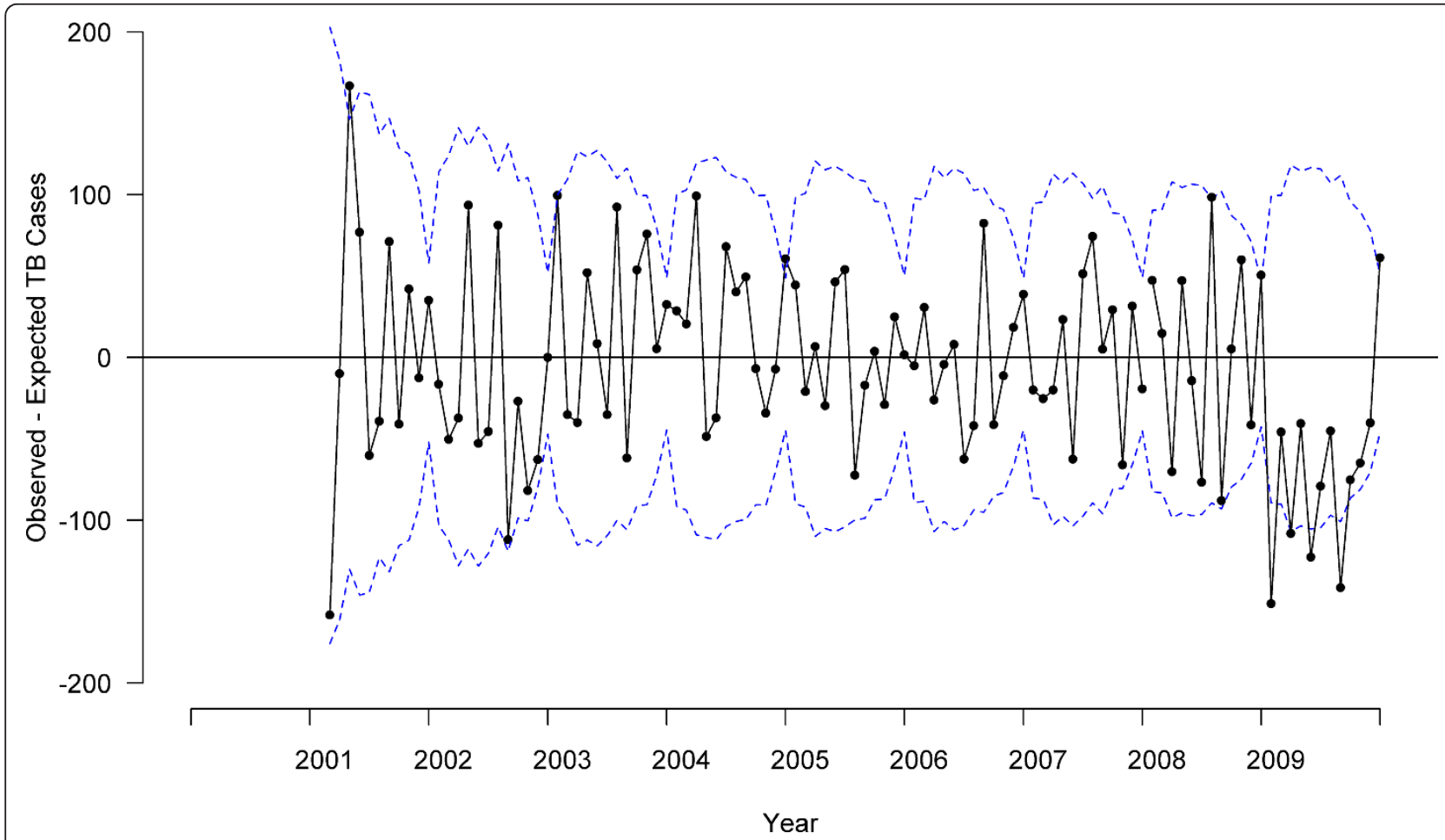

Figure 2 Difference between observed and expected tuberculosis cases by treatment start date, 2000-2009, United States. Solid line indicates the difference between observed and expected tuberculosis case counts based on autoregressive integrated moving average (ARIMA) model, dotted line indicates 95\% confidence interval. 

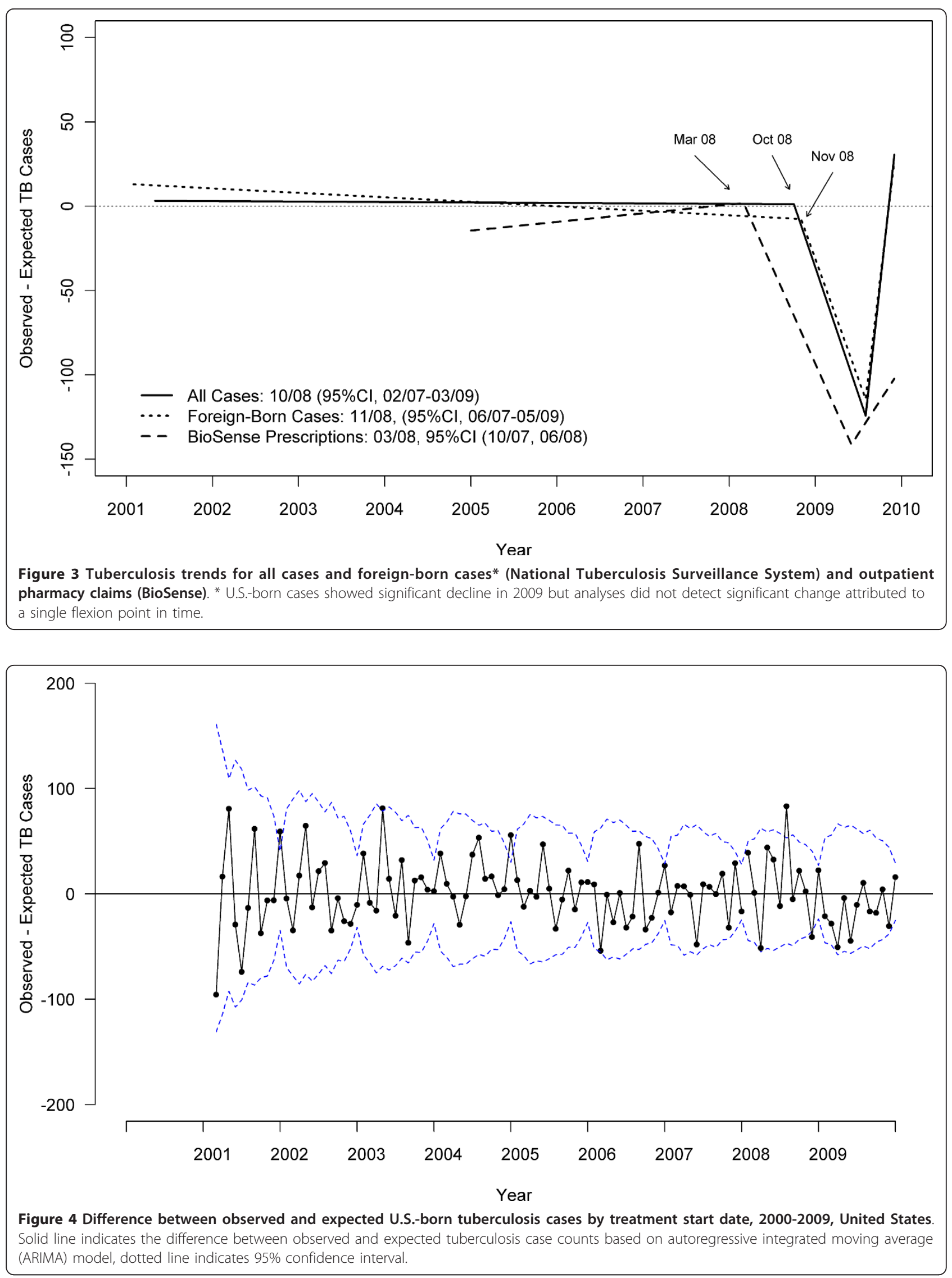


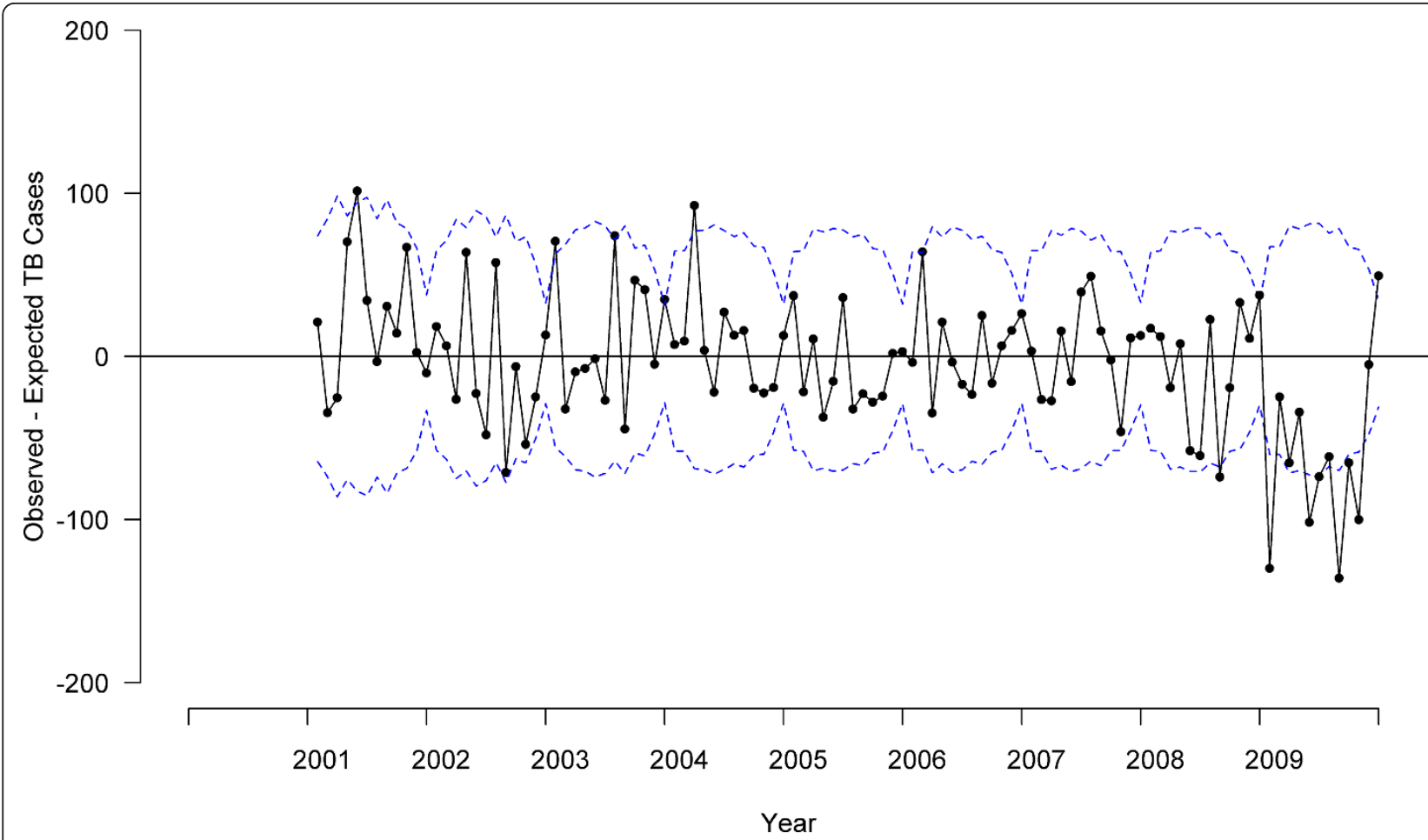

Figure 5 Difference between observed and expected foreign-born tuberculosis cases by treatment start date, 2000-2009, United States. Solid line indicates the difference between observed and expected tuberculosis case counts based on autoregressive integrated moving average (ARIMA) model, dotted line indicates 95\% confidence interval.

declines were seen in states that used new software and well as states that did not. Independent information systems (NTSS, BioSense prescription claims, and public health laboratories) reported similar magnitude declines. Reductions in TB program staff were not associated with greater declines, and TB controllers reported no procedural changes. We found no cases unreported to the NTSS in our examination of over 5400 individual line-listed reports in 11 areas. A detailed study in two states similarly found no evidence of surveillance underreporting [16].

Declines were seen both in culture-positive TB cases and in cases lacking diagnostic laboratory findings. Analyses showed declines particularly among the foreignborn, and among Hispanics and non-Hispanic blacks. Declines were observed among foreign-born persons from countries that implemented new TB procedures for overseas screening and from countries using older procedures for pre-immigration screening. Updated preimmigration screening to identify and treat $\mathrm{TB}$ prior to U.S. arrival is expected to reduce TB in the United States. A recent California study reported decreased TB incidence diagnosed within 6 months of U.S. arrival in persons screened with revised pre-immigration TB screening, compared to persons screened under the older procedures [17]. Authorized immigrants screened prior to U.S. arrival comprise approximately 500,000 arrivals in the United States each year, compared to greater than 160 million annual nonimmigrant admissions among students, temporary workers, diplomats, family members, and visitors, who are not routinely screened prior to U.S. arrival [18]. Because immigration status was not available for analysis of NTSS data, we were not able to adjust for whether foreign-born persons diagnosed with TB in the United States were screened with the revised or older pre-immigration procedures, only whether they originated from a country that had begun to implement updated procedures prior to 2009 .

The unexpected decline in TB cases among the foreign-born could have occurred because of fewer persons entering or more persons leaving the United States. U.S. Census figures estimate a $-1.6 \%$ decline in the foreignborn population from 2008 to 2009. Since there was an $-11.1 \%$ decline in observed compared with expected foreign-born TB cases, the decline in population does not explain the entire decline in foreign-born TB case counts. Our finding that the decline in foreign-born cases was most prominent among those whose TB occurred within 2 years of their arrival, and among 
persons from Mexico and Guatemala (who together comprised $26 \%$ of foreign-born cases), might indicate that the March 2009 Census population data do not accurately reflect population changes in these groups. Department of Homeland Security data suggest greater declines in the foreign-born population in the United States than do Census data, including a $-6.9 \%$ decrease from 11.6 to 10.8 million unauthorized immigrants from 2008 to 2009 [19]. Our finding is consistent with analyses showing that the decline in unauthorized immigrants in the United States is strongly associated with decreased immigration from, and increased deportation to, Mexico [20]. Nonimmigrant authorized admissions to the United States also declined, from 175.4 million in 2008 to 162.6 million in 2009 [18]. Financial data indicate that remittances to Mexico and Latin America began to decline in 2008 and early 2009, consistent with the timing of TB declines, and began to rebound in late 2009 [21].

Case count declines among the U.S.-born were less impressive than among the foreign-born and cannot be substantially explained by less TB transmission from fewer foreign-born cases or by less transmission among the U.S.-born, since genotype clustering among the U. S.-born did not significantly decline from 2008 to 2009 . A limitation of this analysis is that, although genotype clustering is thought to be associated with recent transmission, it is not a direct measure of transmission. Nevertheless, assessment of clustering did not show an abrupt decline in genotype clustering coincident with the abrupt decline in TB cases, suggesting that the decline in cases was not the result of a sudden improvement in TB control practices.

Some of the most dramatic percentage declines occurred among minorities and the socially disadvantaged. These declines may reflect a general problem of delayed access to diagnostic services related to the recent economic recession and some combination of loss of health insurance, fear that seeking medical care might lead to legal consequences, or inability to pay for services [22-24]. We were not able to assess health insurance status or health seeking behavior among TB patients; however, recent national reports of overall declines in physician visits [25] and correlation between unemployment and TB incidence [26] suggest that the decline in reported TB cases may be further evidence of the impact of the economic recession.

Our finding that laboratory reports of culture-confirmed diagnoses of $\mathrm{TB}$ as a proportion of specimens submitted declined more $(-9.8 \%)$ than did the number of patients who had specimens submitted for culture $(-5.9 \%)$ is not consistent with a decline in the index of suspicion for TB among healthcare providers. The abruptness of the decline in cases beginning in late 2008 or early 2009 is also not consistent with this hypothesis.

Although we ruled out surveillance artifact in terms of the total case count, there were increases in missing data in some routinely collected variables, representing small numbers but large increases compared to expectation, which could affect the interpretation of our analyses. For example, if missing data for social risk factors such as injecting drug use and homelessness were complete, our finding of steep declines among persons with these risk factors might either remain unchanged (if missing responses were "no," or were distributed proportional to observed data) or be attenuated to indicate lesser declines (if missing social risk factors were "yes"). Typically, the national surveillance database becomes more complete over time, since TB programs have two years to follow and close out cases in electronic reporting. This incompleteness represents a limitation to using surveillance data for our comparison of observed case counts to expected counts based on prior year counts, which are more complete.

In 2010, provisional NTSS data include 11,181 TB cases reported in the United States, for a rate of 3.6 cases per 100,000 population, which was a decline of $-3.9 \%$ from 2009 similar to the average decline in TB rates (-3.8\% per year) from 2000-2008 [27]. Although the steady decline in TB rates in the United States is evidence of continued progress in TB control, the abrupt decline in 2009 followed by a return to average decline is not consistent with sudden improvements in TB control efforts. Multiple causes coincident with economic recession in the United States, including decreased immigration and delayed access to medical care, could be related to TB declines.

\section{Conclusion}

While a greater-than-expected decline in a deadly infectious disease is usually reason for celebration, our results suggest caution. To the extent that the 2009 TB decline was due to change in immigration patterns, we might expect future increases as the economy improves and the immigrant population increases [28-30]. To the extent that declines represent delays in accessing health care, there might be a greater than expected number of future TB diagnoses, and future cases may be more advanced, more infectious, and more difficult to cure [31]. Ecologic data suggest that rebounds in infectious diseases after economic disruption can have long-standing consequences [32]. To achieve TB elimination in the United States, public health programs must address conditions associated with $\mathrm{TB}$ and with disparities in obtaining health services [33]. 


\section{Acknowledgements}

The authors thank local and state health department staff who collected data included in these analyses. Routine data collected and used in these analyses have been determined to be public health surveillance and not human participants research requiring oversight by an institutional review board. Public use data can be accessed through http://www.cdc.gov/tb/ statistics/default.htm or the Online Tuberculosis Information System at http://wonder.cdc.gov/tb.html with technical instructions at http://wonder. cdc.gov/wonder/help/TB/OTISTechnicalReference.html. Authors thank Carol Pozsik for support of the National Tuberculosis Controllers Association Survey. The National Tuberculosis Controllers Association survey was voluntary and anonymized. We also acknowledge the following participants in local, state, or national investigations: Bisrat Abraham, ljeoma Agulefo, Greg Andrews, Deborah Bedell, Gail Burns-Grant, Jennifer Carter, Cindy Castaneda, Kevin Cain, Eleanor Click, Tracina Cropper, Phyllis Cruise, Dan Dohony, Heather Duncan, Julia Ershova, Vincent Fears, Maria Fraire, Anne Marie France, Regina Gore, Juliana Grant, Vernard Green, Maryam Haddad, Bruce Heath, Andy Heetderks, Andrew Hill, Michael lademarco, Jefferson Jones, Chrispin Kambili, Jimmy Keller, Ann Lanner, Elvin Magee, Lilia Manangan, Sundari Mase, Roque Miramontes, Drew Posey, Chad Heilig, Stuart McMullen, Beverly Metchock, Marisa Moore, Margaret Oxtoby, Farah Parvez, Robert H. Pratt, Lee Ann Ramsey, Edwin Rodriguez, Dan Ruggiero, Neha Shah, Philip Talboy, Vic Tomlinson, Dawn Tuckey, Wanda Walton, Jamie White, and Matthew Willis.

\section{Author details}

'Division of Tuberculosis Elimination, National Center for HIV/AIDS, Viral Hepatitis, STD, and TB Prevention, Centers for Disease Control and Prevention, 1600 Clifton Road NE, Atlanta, GA, 30333 USA. ${ }^{2}$ Northrop Grumman Information Systems, 3375 Northeast Expressway NE, Atlanta, GA 30333, USA. ${ }^{3}$ Public Health Surveillance Program Office, Division of Health Information, Office of Surveillance Epidemiology and Laboratory Services, Centers for Disease Control and Prevention, 1600 Clifton Road NE, Atlanta, GA, 30333, USA. ${ }^{4}$ Tuberculosis Control Program, Kansas Department of Health and Environment, 1000 SW Jackson Street, Topeka, KS, 66612, USA, and Immediate Past President, National Tuberculosis Controllers Association, 2452 Spring Rd SE, Smyrna, GA, 30080, USA.

\section{Authors' contributions}

CAW had full access to all of the data in the study and takes responsibility for the integrity of the data and the accuracy of the data analysis. CAW drafted the manuscript, with sections contributed by TRN, JEB, MPC, AMS, $\mathrm{CH}$, and JSK. CAW, JEB, and MPC designed the overall statistical analysis plan. CAW, TRN, LRA, CJ, RSYW, JW, AMS, CMH, JSK, MCM, SP, JS, AMC, and PG collected and analyzed data and reviewed the findings for interpretation and manuscript for critical intellectual content. CAW, TRN, JEB, LRA, JW, WRM, KM, PAL, and KGC contributed to the study design and interpretation of data as well as critical review and editing of the manuscript. All authors read and approved the final manuscript.

\section{Competing interests}

The authors have no competing interests to report. The findings and conclusions are those of the authors and do not necessarily represent the views of the Centers for Disease Control and Prevention.

Received: 18 March 2011 Accepted: 7 November 2011 Published: 7 November 2011

\section{References}

1. Winston C, Pratt R, Armstrong L, Navin T: Decrease in reported tuberculosis cases - United States, 2009. MMWR 2010, 59:289-294.

2. Centers for Disease Control and Prevention: Tuberculosis (Mycobacterium tuberculosis) 2009 case definition.[http://www.cdc.gov/osels/ ph_surveillance/nndss/casedef/tuberculosis_current.htm].

3. Centers for Disease Control and Prevention: Tuberculosis (Mycobacterium tuberculosis) 1996 case definition.[http://www.cdc.gov/osels/ ph_surveillance/nndss/casedef/tuberculosis_1996.htm].

4. Centers for Disease Control and Prevention: The revised Report of Verified Case of Tuberculosis fact sheet, 2009.[http://www.cdc.gov/tb/publications/ factsheets/statistics/rvct.htm].
5. Hall R, Feldstein M, Frankel J, Gordon R, Poterba J, Stock J, Watson M: Business Cycle Dating Committee, National Bureau of Economic Research.[http://www.nber.org/cycles/sept2010.html].

6. Centers for Disease Control and Prevention: CDC immigration requirements: technical instructions for tuberculosis screening and treatment.[http://www.cdc.gov/immigrantrefugeehealth/pdf/tuberculosis-ti2009.pdf].

7. Small PM, Hopewell PC, Singh SP, Paz A, Parsonnet J, Ruston DC, Schecter GF, Daley CL, Schoolnik GK: The epidemiology of tuberculosis in San Francisco. A population-based study using conventional and molecular methods. N Engl J Med 1994, 330:1703-1709.

8. Ellis BA, Crawford JT, Braden CR, McNabb SJ, Moore M, Kammerer S: Molecular epidemiology of tuberculosis in a sentinel surveillance population. Emerg Infect Dis 2002, 8:1197-1209.

9. Centers for Disease Control and Prevention: Reported tuberculosis in the United States, 2008. Atlanta, GA: U.S. Department of Health and Human Services; 2009 .

10. U.S. Census Bureau: Current Population Survey annual estimates of the United States foreign-born and native resident populations.[http:// dataferrett.census.gov].

11. Centers for Disease Control and Prevention: About Biosense 2009.[http:// www.cdc.gov/biosense/].

12. Centers for Disease Control and Prevention: TB Genotyping Information Management System (TB GIMS) 2010.[http://www.cdc.gov/tb/publications/ factsheets/statistics/gims.htm].

13. National Cancer Institute: Joinpoint Regression Program.[http://surveillance. cancer.gov/joinpoint/].

14. Borgdorff MW, van den Hof S, Kremer K, Verhagen L, Kalisvaart N, Erkens C, van Soolingen D: Progress towards tuberculosis elimination: secular trend, immigration and transmission. Eur Respir J 2010, 36:339-347.

15. Chin DP, DeRiemer K, Small PM, de Leon AP, Steinhart R, Schecter GF, Daley CL, Moss AR, Paz EA, Jasmer RM, Agasino CB, Hopewell PC: Differences in contributing factors to tuberculosis incidence in U.S. -born and foreign-born persons. Am J Respir Crit Care Med 1998, 158:1797-1803.

16. Viner $K$, Johnson CC, Newbern EC, Dickman B, Dettinger L, Waller $K$, Sales $R$, Mitruka K, Magee E, Grant J, Manangan L, Yelk-Woodruff R, Ershova J, Metchock B, Bedell D, Avant W, Dohony D, Cropper TC, Haddad M, Jones J, Rosen T, Click E, Willis M, Abraham B: Assessment of declines in reported tuberculosis cases - Georgia and Pennsylvania, 2009. MMWR 2011, 60:338-342.

17. Lowenthal P, Westenhouse J, Moore M, Posey DL, Watt JP, Flood J: Reduced importation of tuberculosis after the implementation of an enhanced pre-immigration screening protocol. Int J Tuberc Lung Dis 2011, 15:761-766.

18. United States Department of Homeland Security: Yearbook of Immigration Statistics: 2009. Washington, DC: Office of Immigration Statistics, U.S. Department of Homeland Security; 2010.

19. Hoefer M, Rytina N, Campbell C: Estimates of the unauthorized immigrant population residing in the United States: January 2009. Washington, DC: Office of Immigration Statistics, Policy Directorate, U.S. Department of Homeland Security; 2010.

20. Passel JS, Cohn D: Unauthorized immigrant population: national and state trends, 2010. Washington, DC: Pew Hispanic Center; 2011.

21. Ratha D, Mohapatra S, Silwal A: Outlook for remittance flows 2011-2013. Washington, DC: Migration and Remittances Unit, World Bank; 2011.

22. Achkar JM, Sherpa T, Cohen HW, Holzman RS: Differences in clinical presentation among persons with pulmonary tuberculosis: a comparison of documented and undocumented foreign-born versus US-born persons. Clin Infect Dis 2008, 47:1277-1283.

23. Asch S, Leake B, Anderson R, Gelberg L: Why do symptomatic patients delay obtaining care for tuberculosis? Am J Respir Crit Care Med 1998, 157:1244-1248.

24. Golub JE, Bur S, Cronin WA, et al: Patient and health care system delays in pulmonary tuberculosis diagnosis in a low-incidence state. Int I Tuberc Lung Dis 2005, 9:992-998.

25. Johnson A, Rockoff JD, Mathews AW: Americans cut back on visits to the doctor. Wall Street Journal; 2010.

26. Holland DP, Person AK, Stout JE: Did the 'Great Recession' produce a depression in tuberculosis incidence? Int J Tuber Lung Dis 2011, 15:700-702. 
27. Pratt $R$, Price $S$, Miramontes $R$, Navin T, Abraham BK: Trends in tuberculosis - United States, 2010. MMWR 2011, 60:333-37.

28. Cain KP, Benoit SR, Winston CA, Mac Kenzie WR: Tuberculosis among foreign-born persons in the United States. JAMA 2008, 300:405-412.

29. Cain KP, Mac Kenzie WR, Castro KG, LoBue PA: No man is an island: reducing diagnostic delays in undocumented foreign-born persons is needed to decrease the risk of tuberculosis transmission. Clin Infect Dis 2008, 47:1284-1286.

30. LoBue PA, Moser KS: Screening of immigrants and refugees for pulmonary tuberculosis in San Diego County, California. Chest 2004, 126:1777-82.

31. Golub JE, Bur S, Cronin WA, et al: Delayed tuberculosis diagnosis and tuberculosis transmission. Int J Tuberc Lung Dis 2006, 10:24-30.

32. Dye C, Williams BG: The population dynamics and control of tuberculosis. Science 2010, 328:856-861.

33. Castro KG, LoBue P: Bridging implementation, knowledge, and ambition gaps to eliminate tuberculosis in the United States and globally. Emerg Infect Dis 2011, 17:337-342.

\section{Pre-publication history}

The pre-publication history for this paper can be accessed here: http://www.biomedcentral.com/1471-2458/11/846/prepub

doi:10.1186/1471-2458-11-846

Cite this article as: Winston et al:: Unexpected decline in tuberculosis cases coincident with economic recession - United States, 2009. BMC Public Health 2011 11:846.

\section{Submit your next manuscript to BioMed Central and take full advantage of:}

- Convenient online submission

- Thorough peer review

- No space constraints or color figure charges

- Immediate publication on acceptance

- Inclusion in PubMed, CAS, Scopus and Google Scholar

- Research which is freely available for redistribution

Submit your manuscript at www biomedcentral.com/submit 